\title{
ADHESIÓN TERAPÉUTICA: REVISIÓN HISTÓRICA Y ESTADO DE LA CUESTIÓN EN LA INFECCIÓN POR VIH/SIDA
}

\author{
RAFAEL BALLESTER \\ Universidad Jaime I de Castellón
}

(Aceptado en octubre de 2002)

\begin{abstract}
La infección por VIH/SIDA se ha convertido en las últimas dos décadas en una de las prioridades para los sistemas sanitarios de todo el mundo tanto por su prevalencia (la pandemia afecta ya a cerca de $\mathbf{4 0}$ millones de personas) como por la gravedad de la enfermedad. En los últimos años se han producido importantísimos avances en el tratamiento farmacológico de los enfermos con $\mathrm{VIH}$, con el desarrollo de nuevos y más potentes antirretrovirales. Sin embargo, los investigadores y clínicos denuncian una alta tasa de problemas de adhesión al tratamiento en los pacientes que anula en muchos casos los beneficios derivados de los progresos médicos. En este artículo presentamos una revisión teórica de los antecedentes de investigación psicológica sobre la adhesión a los tratamientos, analizamos la problemática específica que se encuentra en este aspecto en el caso del SIDA y revisamos brevemente los principales estudios acerca de la eficacia de diversos programas de intervención cognitivo-conductual desarrollados hasta el momento para la mejora de la adhesión a los antirretrovirales en estos pacientes.
\end{abstract}

Palabras clave: VIH/SIDA, adhesión terapéutica, revisión teórica.

\section{Treatment adherence: An historical review and state of question in HIV} Infection/AIDS

HIV infection/AIDS has become at the last two decades one of the priorities for the health systems in all the world because its prevalence (near of 40 millions of persons affected) and the seriousness of disease. At last years important advances in the field of pharmacological treatment of HIV infection patients have been produced, with the development of new and more potent antiretrovirals. Nevertheless, researchers and clinicians report a high rate of problems related with adherence that invalidate benefits derived from medical advances. At this paper we present a theoretical review of antecedents of psychological research about adherence to treatments. Also, we analyze specifics problems found in AIDS patients and review studies about effectiveness of cognitive-behavioral programs of intervention to increase adherence to antiretrovirals in HIV infection patients.

Key words: HIV/AIDS, adherence to treatment, theoretical review.

Cuando una persona sufre algún mal que es superior a los medios de la medicina, no se ha de esperar, en modo alguno, que éste pueda ser superado por la medicina (Hipócrates, Sobre la Ciencia Médica, 8)

Correspondencia: Dpto. Psicología Básica, Clínica y Psicobiología, Facultad de Ciencias Humanas y Sociales, Universitat Jaume I de Castelló, 12080 Castellón. Tel.: 964728000 . Correo-e: rballest@psb.uji.es

Nota: Este trabajo ha sido posible en parte gracias a las ayudas para la realización de proyectos de investigación concedidas por el Plan del SIDA de la Direcció General de Salut Pública de la Generalitat Valenciana $(1 / 2000)$ y por la Universitat Jaume I de Castello-Fundació Bancaixa (P1.1 A 2000-05).

\section{UN ANTIGUO PROBLEMA}

El reconocimiento, la preocupación y la protesta por el hecho de que a menudo los pacientes no siguen las prescripciones de los profesionales de la salud, sean éstos médicos, psicólogos o enfermeros, se remontan a tiempos muy antiguos. Ya Hipó- 
crates (siglo v a.C), que como se sabe es considerado el primer gran antecedente de la medicina moderna, afirmaba en algunos de sus escritos que algunos pacientes mentían al médico cuando eran interrogados acerca de si habían tomado sus medicinas. En el Corpus Hipocraticum se habla de loserrores y engaños de los enfermos en "Sobre la decencia» y en "Prorrético» (II, 3 y 4). Así, en la primera de las obras mencionadas, Hipócrates dice:

«Hay que vigilar también los errores de los enfermos, que muchas veces te engañan en cuanto a la toma de las cosas prescritas y que, por no tomarse pociones desagradables $u$ otros medicamentos o tratamientos, son llevados a la muerte. $Y$ por su parte, no se inclinan a reconocer lo que han hecho, sino que es al médico al que culpan» (Sobre la Decencia, 14).

Desde la medicina hipocrática, el resultado de lo que hoy llamamos falta de adhesión a los tratamientos era considerado como un obstáculo para la curación del paciente, especialmente si tenemos en cuenta que Hipócrates, al igual que Galeno siete siglos después, consideraba que el arte del médico consistía simplemente en ayudar a la naturaleza en su esfuerzo curativo. El papel del enfermo era fundamental en este proceso natural de curación. Podemos encontrar la expresión de esta idea en el siguiente pasaje de Hipócrates: «El oficio se forma sobre tres factores: la enfermedad, el enfermo y el médico. El médico es un servidor de su oficio. El paciente ha de enfrentarse a la enfermedad con ayuda del médico» (Epidemias, I, 11). También en sus «Aforismos» (1) dice «Es preciso no sólo disponerse a hacer lo debido uno mismo (el médico), sino además (que colaboren) el enfermo, los que le asisten y las circunstancias externas».

Según Turk y Meichenbaum (1991), a pesar de que el incumplimiento por parte de los pacientes de las prescripciones médicas es un fenómeno antiguo, el inte- rés por investigar la adhesión empíricamente y por promoverla es un hecho mucho más reciente que se remonta apenas a la década de los 70 . Sería a partir de esta fecha cuando los avances médicos y farmacológicos que aumentaban de forma importante las posibilidades de curación del enfermo hicieron ver por primera vez que la no adhesión a los tratamientos prescritos podía tener realmente consecuencias muy perjudiciales para el enfermo. Por otra parte, estos autores señalan que otra diferencia que encontramos a partir de esta etapa es el reconocimiento de que la falta de adhesión puede ser, en parte, un problema del médico y no tan sólo del paciente.

Aunque en líneas generales nosotros estamos de acuerdo con Turk y Meichenbaum en que hasta hace apenas tres décadas no se investigaba empíricamente la falta de adhesión de los pacientes y no se disponía de grandes medios para evaluar y combatir esta falta de adhesión, no lo estamos tanto en los argumentos esgrimidos por estos autores. En primer lugar, desde nuestro punto de vista, el ser humano, desde los inicios de la humanidad, siempre ha puesto todos los medios que sus conocimientos y grado de desarrollo técnico le han permitido para luchar contra la enfermedad y la muerte. Es cierto que los avances médicos y farmacológicos en los dos últimos siglos y más concretamente en las últimas décadas ha sido asombroso y nos permiten curar enfermedades que hasta hace poco eran fatales para el individuo. Pero también es cierto que los métodos de curación más o menos científicos han existido desde siempre. Y no nos estamos refiriendo a métodos más o menos mágicos basados en rituales, sino a prácticas médicas o fármacos como los que podemos encontrar en los Papiros egipcios de Ebers y de Smith (Ballester, 1998). Hacemos nuestra la reflexión de Temkin (1977) cuando señala que la Medicina es 
tratamiento (y prevención) basado en los conocimientos que se consideren necesarios. Estos conocimientos pueden ser teológicos, mágicos, empíricos, racionales y especulativos o científicos. El hecho de que nuestra medicina actual se base en gran parte en una ciencia no hace que otras formas de curar sean menos médicas, aunque pensemos que fueran menos efectivas. Por ello, pensamos, es de suponer que si desde antiguo han existido remedios curativos que se han considerado efectivos para el tratamiento de las enfermedades, también desde antiguo se habrá considerado que la falta de adhesión a esos remedios curativos tendría consecuencias fatales. Se reprocha a la Antigüedad, hasta el siglo XIX, que en aquellos tiempos la falta de adhesión quizás tuvo un sentido adaptativo, ya que algunos de los remedios podían llevarse por delante la vida de muchas personas (Davidson, 1982). Pero, ¿no nos sobran ejemplos de cómo tratamientos recientes que han sido considerados muy efectivos en un momento dado, han sido prohibidos a continuación por su alto grado de toxicidad o por su peligrosidad? (la talidomida podría ser uno de esos ejemplos).

Por otra parte, al menos desde los tiempos de Hipócrates, se ha sido consciente del importante papel que desempeñaba el médico para promover la adhesión de sus pacientes al tratamiento. Por ejemplo, encontramos pasajes de este autor en los que se da instrucciones directas al médico para que facilite el afrontamiento de la enfermedad al paciente y promueva la adhesión. Así, de nuevo en «Sobre la Decencia» (16) Hipócrates afirma:

«Dale las órdenes oportunas con amabilidad y dulzura, y distrae su atención; repréndele a veces estricta y severamente, pero otras, anímale con solicitud y habilidad... En la misma obra (17), Hipócrates señala: «Deja a uno de tus discípulos junto al enfermo para que éste no utilice mal tus prescripciones y lo ordenado por ti cumpla su función".
De manera más indirecta, sin referirse estrictamente al cumplimiento por parte de los pacientes de las prescripciones terapéuticas, Hipócrates da numerosas indicaciones de la importancia que tiene en el proceso de curación la relación médico-paciente, la comunicación entre ambos, el uso de un lenguaje inteligible para el enfermo y el modo de presentarse el médico ante este último, tal como puede apreciarse en los siguientes pasajes:

«Es fundamental, en mi opinión, que el que habla de este arte diga cosas inteligibles para los profanos, ya que no le compete ni investigar ni hablar de algo distinto a las dolencias que ellos mismos padecen y sufren". (Sobre la Medicina Antigua, 2).

«En cuanto a su porte, muéstrese preocupado en su rostro, pero sin amargura. Porque, de lo contrario, parecerá soberbio e inhumano... Sea justo en cualquier trato, ya que la justicia le será de gran ayuda. Pues las relaciones entre el médico y sus pacientes no son algo de poca monta» (Sobre el médico, 1).

"Y debe estar muy pendiente de sí mismo sin exhibir demasiado su persona ni dar a los profanos más explicaciones que las estrictamente necesarias, pues eso suele ser forzosamente una incitación a enjuiciar el tratamienton. (Sobre la decencia, 7).

«En la visita ten presente la forma de sentarte, la compostura, el atuendo, el porte de autoridad, la parquedad de palabras, la actitud serena, la atención constante, la dedicación, la réplica a las objeciones, el dominio de ti mismo ante las dificultades que surjan, la severidad para dominar la situación en momentos de alarma y la prontitud para actuar" (Sobre la decencia, 12).

También Galeno (S. II d.C.) en su «Sobre la localización de las enfermedades» daba una gran importancia a la comunicación médico-paciente y concretamente a la palabra en el tratamiento del enfermo. La palabra como recurso diagnóstico era fundamental en dos planos: por una parte, para interrogar al enfermo $y$, por otra, para informarle sobre su enfermedad y el tratamiento. En sus descripciones de enfermedades se adivinan horas de conversación con 
sus enfermos en las que, entre otras cosas, se indagaba todo lo relacionado con la vida anímica (temor, ira, alegría, tristeza...) de éstos con el fin de poder proporcionarle el tratamiento más ajustado a su situación.

Por tanto, nosotros pensamos que cuando hablamos de falta de adhesión a los tratamientos estamos hablando de un fenómeno antiguo y también de una preocupación antigua de los sanadores. Uno de los motivos de la falta de adhesión, como por ejemplo, la desconfianza respecto a las prescripciones médicas está recogido en el saber popular de nuestros refranes como el que dice «Más mató la receta que la escopeta». Tampoco nos resulta raro oír hablar de los "matasanos» en nuestra cultura. Especialmente desde mediados del siglo XVI a mediados del siglo XVIII en nuestra literatura encontramos innumerables pasajes que no dejan en demasiado buen lugar a los médicos y sus métodos de curación (Díaz-Plaja, 1996). Por poner algunos ejemplos, el lector puede encontrar suficientes referencias en este sentido en autores como Antonio de Guevara (1481-1545) en sus «Epístolas familiares», Esteban de Garibay (1493-1549) en sus «Cuentos», Góngora (1561-1627) en sus «Letrillas», Quevedo (1580-1645) en su «La visita de los Chistes», Tirso de Molina (1579-1648) en «El amor médico», Cervantes (1574-1616) en «El Quijote», Calderón de la Barca (1600-1681) en "El médico de su honra» o Diego Torres de Villarroel (1693-1770) en «Memorias». Parece, por tanto, que siempre ha habido problemas de adhesión y también ha habido conciencia por parte de profesionales y enfermos de algunas de las causas de este problema. Lo que quizás resulte mucho más moderno es, además de la investigación empírica acerca de los factores causantes de la falta de adhesión, la conciencia reivindicativa de los enfermos como usuarios del sistema sanitario acerca de sus derechos y el cuestionamiento del omnipotente poder de la autoridad escolapia. La libertad individual abanderada en los movimientos de los años 60 fue catapultada también al ámbito sanitario, donde de repente el enfermo se hizo consciente de su derecho de decidir y su poder para actuar en relación con su salud. La pasividad y la "paciencia» del paciente fueron cuestionadas y sustituidas por el malestar, la reivindicación y los litigios.

\section{UNAS PALABRAS ACERCA DEL CONCEPTO DE ADHESIÓN TERAPÉUTICA Y SU EVALUACIÓN}

Durante mucho tiempo se han utilizado de forma indistinta los términos «adherencia», "adhesión», "cumplimiento»y «obediencia». Los dos primeros términos harían, en principio, referencia al mismo concepto. Aunque los dos son correctos, en realidad, el término "adhesión», desde nuestro punto de vista, sería más adecuado en nuestra lengua, ya que «adherencia» es una traducción demasiado literal del inglés "adherence». En el Diccionario de la Real Academia Española, "Adhesión» sería la «acción y efecto de adherir o adherirse, conviniendo en un dictamen o partido». "Adherencia» hace más referencia a la «unión física, pegadura de las cosas", aunque también es "calidad de adherente». Sin embargo, el término "cumplimiento» (traducido del inglés compliance) sí que contiene connotaciones e implicaciones muy diferentes al de adhesión. En el Diccionario de la Real Academia Española, cumplimiento es la «acción o efecto de cumplir», esto es de «hacer alguien aquello que debe o a que está obligado». El cumplimiento se refiere al grado en que los pacientes siguen escrupulosamente las instrucciones y las prescripciones de sus 
profesionales sanitarios. Muchos autores entre los que se encuentran Eisenthal, Emery, Lazare y Udin (1979) o Kristeller y Rodin (1984) defienden que el término "cumplimiento" introduce la connotación de un rol pasivo por parte del paciente y que su contrario, el término "incumplimiento» contiene en sí mismo un componente valorativo que implica una actitud negativa hacia el paciente haciéndole responsable de esa falta de cumplimiento. Sin embargo, desde nuestro punto de vista, no parece, en principio, esperable que un paciente «deba» o tenga la obligación de cumplir con un tratamiento que, por ejemplo, no le ha sido suficientemente explicado.

Finalmente, nosotros pensamos que el término «obediencia terapéutica» sería totalmente inadecuado ya que todavía enfatiza más el carácter unidireccional de la relación médico-paciente y del poder y autoridad que el primero debe ejercer sobre el segundo. La responsabilidad de la falta de obediencia recaería completamente en el paciente y las consecuencias deberían ser soportadas como un efecto de la actitud de éste ante su enfermedad. «Obedecer» es "cumplir la voluntad de quien manda» según nuestro Diccionario, así que sobran las palabras respecto a la inconveniencia de este término. En contra de tales connotaciones, el término adhesión supone una implicación más activa y voluntaria de colaboración del paciente dentro de una relación mutuamente aceptable que tiene como consecuencia un resultado preventivo o terapéutico deseable (Meichenbaum y Turk, 1991).

El concepto de "adhesión terapéutica» es un concepto complejo. No existe una dicotomía perfecta entre la adhesión y la no-adhesión terapéutica. En realidad, los pacientes suelen mostrar distintos grados de adhesión en diferentes aspectos de su enfermedad y de su tratamiento. Por ejemplo, un paciente podría mostrar gran adhesión al tratamiento en cuanto que se toma todos y cada uno de los fármacos, pero escasa adhesión porque no se los toma a las horas y en las condiciones indicadas. O podría ser que también se tomara los fármacos a las horas indicadas pero, sin embargo, no siguiera las recomendaciones de su médico respecto al cuidado de la dieta y la realización de ejercicio físico. Incluso, como señalaba Blackwell (1979) las razones de la falta de adhesión de los pacientes pueden ser diferentes para las distintas facetas del tratamiento. Por ejemplo, el olvido puede ser un factor más importante para no tomar la medicación que para el seguimiento de las visitas médicas. Y la falta de tiempo, podría ser, viceversa, un factor que explicase más el hecho de no acudir a las visitas médicas que el de no tomar el tratamiento. El estigma asociado a algunas enfermedades, entre las que se encuentra el SIDA, podría hacer que algunas personas que temen ser reconocidas en el hospital, no acudan a la consulta médica, mientras que en principio no tendría que estar muy relacionada con la toma de medicación y el seguimiento de las recomendaciones del médico en lo que respecta al cambio de los hábitos de salud.

Tampoco es sencilla la relación entre la adhesión y los resultados terapéuticos. En el tratamiento de una enfermedad puede ser esencial que el paciente se adhiera a las condiciones de tratamiento, pero eso no significa que la adhesión garantice un éxito total en el sentido de impedir que la enfermedad avance o se agrave. Lo contrario también es cierto. Son muchos los factores que intervienen en la progresión de una enfermedad y la adhesión es uno de ellos. Aunque muy importante, sólo es uno de ellos y esa falta de relación directa entre la adhesión y los resultados terapéuticos puede desanimar a muchos pacientes adherentes y hacer albergar excesivas esperanzas en otros pacientes no-adherentes. 
La complejidad del fenómeno de la adhesión terapéutica lleva aparejada la necesidad de una evaluación también compleja que permita obtener información de diferentes aspectos relacionadas con la misma. Fundamentalmente, hasta el momento se ha utilizado para esta evaluación, el autoinforme, el recuento de pastillas, la monitorización fisiológica y bioquímica y el resultado terapéutico.

El autoinforme del paciente es el método más fácil y más frecuentemente usado ya que tan sólo se trata de preguntar al paciente si ha tomado su medicación o pedirle que registre el tipo de comportamiento deseado. Ha recibido críticas importantes por la posibilidad de que sea inexacto, por el efecto reactivo de la observación y por el efecto de la deseabilidad social en la respuesta de los pacientes (Roth, 1987). Sin embargo, a pesar de estas limitaciones, muchos autores han destacado que el autoinforme de los pacientes puede predecir bastante bien la conducta real de éstos (Dunbar y Agras, 1980; Morisky, Green y Levine, 1986).

El recuento de pastillas es el método conductual más utilizado para evaluar la adhesión. Aquí el profesional da al paciente una cierta cantidad o un bote de pastillas y éste debe devolver las pastillas no ingeridas pasado un tiempo. Se considera que la resta entre las pastillas iniciales y las finales son la medicación que el paciente ha tomado. Sin embargo, este método tiene algunos problemas. En primer lugar, el hecho de que un cierto número de pastillas ya no estén no nos asegura que el paciente se las haya tomado, por lo que también aquí hay posibilidades de inexactitud como ocurría en el autoinforme. Además, el porcentaje de pastillas tomadas es un indicador demasiado grueso ya que no nos habla de si las pastillas han sido tomadas a las horas indicadas o en las condiciones adecuadas.

En tercer lugar, la monitorización fisiológica o bioquímica, consiste en el análi- sis de la orina o de la sangre del paciente con el fin de detectar los niveles del fármaco en su metabolismo. Evidentemente los sesgos de los que hemos hablado hasta el momento no afectan a este tipo de medida de la adhesión. Sin embargo, eso no significa que no esté exenta de problemas. Por ejemplo, los análisis de orina sólo son sensibles a la toma de medicación dos o tres días antes de la analítica y además los resultados pueden variar en función de la metabolización del fármaco. Por lo tanto, tan sólo tenemos una medida de las últimas tomas de medicación que pueden no ser representativas de la adhesión del paciente a lo largo del tratamiento. A eso tendríamos que añadir otros problemas como su alto coste, el hecho de ser un método poco práctico en la clínica, la limitada disponibilidad de este tipo de medidas en muchos casos y, como hemos señalado antes, su vulnerabilidad a variaciones en función de la vida media del fármaco y las condiciones metabólicas.

Finalmente, los resultados clínicos pueden ser un indicador de hasta qué punto el paciente observa el tratamiento. Sin embargo, utilizar este método supone partir de la base de que el tratamiento que está recibiendo el paciente es el óptimo, lo cual no siempre es cierto, que no existen otras variables intervinientes en la progresión de la enfermedad y que por lo tanto existirá una relación directa entre el grado de mejoría del paciente y su adhesión. Sabemos que esto no es así, tenemos muchos datos relacionados con distintas enfermedades que nos indican que en ocasiones los pacientes mejoran sin por ello haber seguido el tratamiento y también lo contrario, a veces no mejoran a pesar de estar siguiendo éste de forma muy estricta, lo que hace que tampoco este método sea perfecto para intuir la adhesión terapéutica.

Como se puede observar, todos los métodos de evaluación de la adhesión 
terapéutica pueden presentar problemas $y$, en principio, son cuestionables, pero también hay muchos estudios que avalan su eficacia como métodos de evaluación. Quizás lo más adecuado, cuando resulta factible es una combinación de dos o más de ellos. En el ámbito específico de la infección por VIH la búsqueda de nuevos métodos innovadores para la evaluación de la adhesión sigue siendo una prioridad para los investigadores (Wagner y Rabkin, 2000; Samet, Sullivan, Traphagen e Ickovics, 2001).

\section{ALGUNOS ANTECEDENTES DE INVESTIGACIÓN PSICOLÓGICA SOBRE LA ADHESIÓN TERAPÉUTICA}

Aunque, como hemos dicho, el interés y la preocupación por la adhesión terapéutica debe ser considerado como un fenómeno muy antiguo, es a partir de los últimos años de la década de los 60 y sobre todo, a partir de los años 70 cuando la investigación psicológica sobre la adhesión terapéutica y los factores relacionados con la misma se incrementaron de modo notable. Actualmente podemos decir que la literatura científica sobre este tema es ingente y por lo tanto, sería excesivamente pretencioso intentar realizar aquí una revisión exhaustiva de todo lo que se ha investigado al respecto. Sin embargo, nos parece obligado recordar algunos de los trabajos clásicos sobre el tema, que constituyen verdaderos puntos de referencia como los de Davis (1966), Blackwell (1972, 1973, 1979), Kasl (1975), Davidson (1976), Barofsky (1977), Cohen (1979), Kirscht y Rosenstock (1979), DiMatteo y DiNicola (1982), Dunbar y Agras (1980), Friedman y Litt (1986), Gerber y Nehemkis (1986), y Meichenbaum y Turk (1991). La adhesión terapéutica ha llegado a ocupar un lugar prominente dentro de la literatura científica en Psicología de la Salud. Prueba de ello es que el primer manual sobre Psicología de la Salud, el publicado por Stone, Cohen y Adler en 1979 ya incluía el citado trabajo de Kirsch y Rosenstock (1979) sobre los problemas de los pacientes para seguir las recomendaciones de los profesionales de la salud.

Pero, también es cierto que toda esta investigación no surge de manera aisla$\mathrm{da}$, sino que a su vez, forma parte y proviene de un interés de los científicos surgido en años anteriores que recogía inquietudes muy antiguas, que denunciaba las limitaciones de los modelos biomédicos tradicionales en la comprensión de la salud y la enfermedad, que clamaba por la consideración de los aspectos sociales de la misma (recuérdese toda la literatura sobre el rol de enfermo surgida a partir de la obra de Talcot Parsons en 1951) y de las diferencias individuales en la experiencia de enfermedad (recuérdese también la extensa línea de investigación y de publicaciones sobre la conducta de enfermedad, después de que David Mechanic acuñara este concepto en el año 1962) y que culmina en la formulación por parte de Engel del modelo biopsicosocial en 1977, uno de los pilares básicos sobre los que se constituiría la Psicología de la Salud como disciplina en los primeros años de la década de los 80 (para una revisión teórica sobre el tema es posible consultar el libro de Ballester, 1998 o los artículos del mismo autor publicados en $1993 \mathrm{a}, \mathrm{b}$ ).

Como ejemplo de esto que decimos, en el libro que Millon publicó en 1975 bajo el título de Medical Behavioral Science, dos años antes de que Engel formulara su modelo, el autor ya recogía algunos trabajos anteriores que enfatizaban aspectos que darían lugar a un cambio en la concepción del paciente hacia la consideración de éste como un ente activo que merecía ser tratado por el profesional sanitario en toda su globalidad y complejidad. Nos referimos fundamentalmente a 
los trabajos de Lederer (1952), Szass y Hollender (1956), Engel (1962), Elder (1963) y Haney (1971). En primer lugar, Lederer ya en el año 1952 analiza cómo percibe el enfermo su propio mundo y cómo va evolucionando su experiencia de enfermedad a lo largo de la adaptación a la misma. Vemos ya en su trabajo la inquietud por la perspectiva del enfermo que padece la enfermedad. Szass y Hollender, en su artículo publicado un año después, plantean tres modelos básicos de relación paciente-médico: el modelo de actividad-pasividad en el que de manera unidireccional se entiende que el médico ejerce una actividad sobre el paciente que permanece pasivo; el modelo de guía-cooperación en el que el médico dice al paciente lo que debe hacer y éste coopera obedeciéndole; y el modelo de participación mutua, en el que el médico ayuda al paciente a ayudarse a sí mismo desde una consideración totalmente activa de éste último (véase la similitud entre este planteamiento y los que ahora consideramos de gran actualidad y originalidad). Engel, ya en el año 1962, establece las bases de lo que posteriormente sería el modelo biopsicosocial en una crítica feroz al modelo biomédico tradicional. El trabajo de Elder (1963), por su parte, enfatiza ya hace cuatro décadas la importancia de que los profesionales de la salud se preocupen por dar la oportunidad al paciente de expresar sus sentimientos, sus dudas y sus temores, y de que perciban a éstos como personas que les apoyan en el proceso de su enfermedad. Finalmente, Haney en el año 1971 publica un capítulo en el que destaca la influencia de los modelos implícitos y de los valores personales y profesionales del médico en la toma de decisiones que afectan al enfermo.

También desde finales de la década de los 70 especialmente, aumentó la literatura científica sobre la importancia de la relación médico-paciente y más concre- tamente sobre cómo esta relación podía jugar un importante papel en la adhesión al tratamiento (DiMatteo, 1979; Stone, 1979; DiMatteo, 1994; Cameron, 1996; Buchman, 1997). Dentro de esta interacción se han identificado dos componentes esenciales: el intercambio de información (que ya señalara Galeno) y lo que podríamos denominar el carácter afectivo de la relación, incluyendo aspectos como el interés, el respeto, la calidez o la empatía (Morales, 1985; Roter y Hall, 1992; Ong, Haes, Hoos y Lammes, 1995).

En resumen, nos encontramos ante un tema que ya podríamos considerar clásico en Psicología de la Salud, tanto por el número de investigaciones y publicaciones sobre el mismo, como por el hecho de que su estudio surgió de las mismas inquietudes que dieron luz a esta disciplina.

En general, los estudios que hasta el momento se han dirigido a explorar la adhesión al tratamiento ante distintas enfermedades han remarcado la influencia de cinco tipo de factores sobre la misma (ver Tabla 1), que Meichenbaum y Turk (1991) resumen muy bien y que simplemente reseñaremos.

En primer lugar, los factores relacionados con el paciente incluyen aspectos tan distintos como las características del individuo, la existencia o no de un trastorno psicológico, la existencia de alguna discapacidad sensorial, el olvido o el descuido, las creencias relacionadas con la salud, la enfermedad y el tratamiento, las expectativas inadecuadas acerca del tratamiento, creencias socioculturales relacionadas con la enfermedad, el modelo implícito de enfermedad, la apatía o pesimismo respecto a las posibilidades de curación, la dificultad para darse cuenta de que se está enfermo o se necesita medicación, la historia previa de adhesión a otros tratamientos, insatisfacción con el profesional o con el tratamiento, la situación social del individuo, la falta de apoyo social, la estabilidad y armonía familiar, la estabili- 
dad o no de la vivienda, la existencia de otras demandas que compitan con la adhesión como la pobreza o el desempleo y finalmente, la falta de recursos que podrían favorecer la adhesión como el dinero o los medios de transporte.

En segundo lugar, se encuentran los factores relacionados con la enfermedad como por ejemplo, el hecho de que estemos ante una enfermedad crónica con ausencia de síntomas manifiestos o ante una enfermedad aguda o con sintomatología evidente, la estabilidad de los síntomas y las características asociadas a la enfermedad o dolencia, como el tipo y grado de incapacidad que produce.

En tercer lugar, entre los factores relacionados con el tratamiento al que pedimos al paciente que se adhiera se hallan la complejidad del régimen de tratamiento, como por ejemplo, el hecho de tener que tomar muchas medicaciones distintas, la duración de la enfermedad, el grado de cambio comportamental requerido como en el caso de enfermedades que exigen grandes alteraciones en el estilo de vida de la persona, los efectos secundarios de la medicación, el coste de la misma, el formato de la medicación y su modo de administración (p.ej., cápsulas, tabletas o inyecciones), factores que pueden parecer tan triviales como el color y tamaño de las pastillas, el tipo de etiquetas de la medicación y la comodidad del diseño del recipiente.

En cuarto lugar, se agrupan aquellos factores que se relacionan con la institución sanitaria de los que no son responsables ni el médico ni el paciente, entre los que se encuentran la continuidad o discontinuidad del cuidado médico, el tiempo de espera, el intervalo de tiempo entre el primer contacto y la consulta, la falta de asignación de un tiempo para cada cita, la falta de cohesión en el sistema sanitario, inconvenientes asociados al centro de salud como el horario, la amabilidad del personal o la disponibilidad de aparcamiento, la reputación sobre las instalaciones o medios para dar el tratamiento y la adecuación de la supervisión por parte de los profesionales sanitarios.

Finalmente se encuentran los factores relacionados con la relación o interacción entre el paciente y el profesional de la salud, dentro de los cuales se podría mencionar la comunicación entre ambos, las actitudes y conductas verbales y no verbales por parte de médico y paciente, las dificultades del profesional para elicitar las preocupaciones, sentimientos o emociones negativas del paciente, la insatisfacción de éste último sobre la relación o la supervisión inadecuada del profesional de la salud.

Como se puede observar, los factores que, en general, se consideran asociados a la adhesión terapéutica se relacionan con los distintos elementos que intervienen en la ecuación: el paciente, el profesional sanitario, la relación entre ambos, las características del sistema o institución sanitaria y finalmente, de modo muy importante, aquello que relaciona o pone en contacto a estos elementos, a saber, la enfermedad. Probablemente muchos de los factores que influyan en la adhesión terapéutica de los pacientes con infección por VIH sean comunes a los que influyen en la adhesión de pacientes con otras enfermedades graves y crónicas. Sin embargo, la infección por VIH tiene, como enfermedad, algunas características ciertamente peculiares, como por ejemplo, el estigma social asociado a esta enfermedad, el número de fármacos necesarios para su tratamiento, la importancia de muchos de los efectos secundarios de tales fármacos o las circunstancias que rodean la vida de muchos de los afectados. Por ello, a continuación analizaremos cuál es la importancia de la adhesión al tratamiento en la infección por VIH y cuáles son los factores que hasta el momento se han relacionado con tal adhesión. 
Tabla 1. Factores relacionados con la falta de adhesión al tratamiento

\section{Factores relacionados con el paciente}

- Características del individuo

- Tipo y gravedad del diagnóstico psiquiátrico (particularmente, diagnóstico de esquizofrenia, trastorno afectivo bipolar, trastorno paranoide o trastorno de personalidad)

- Discapacidad sensorial

- Olvido o descuido

- Falta de comprensión

- Creencias relacionadas con la salud inapropiadas (p.ej., ideas erróneas, falta de comprensión de la profilaxis y creencias de que la medicina es necesaria sólo cuando están presentes los síntomas)

- Expectativas inapropiadas acerca del tratamiento

- Creencias populares socioculturales o étnicas relacionadas con la enfermedad y el tratamiento

- Modelos implícitos de enfermedad

- Apatía y pesimismo

- Dificultad para darse cuenta de que uno está enfermo o necesita medicación

- Historia actual o previa de no adhesión a otros regímenes de tratamiento

- Insatisfacción con el profesional o con el tratamiento

- Características de la situación social del individuo

- Falta de apoyo social

- Inestabilidad o falta de armonía familiar

- Contexto favorecedor de la no adherencia (p.ej., inestabilidad en la vivienda)

- Demandas que compiten o entran en conflicto con la adherencia (p.ej., pobreza o desempleo)

- Falta de recursos (transporte, dinero o cuidado de los niños)

Factores relacionados con la enfermedad

- Condición crónica con ausencia de sintomatología manifiesta

- Estabilidad de los síntomas

- Características relacionadas con la enfermedad (confusión, probl. visuales, reacciones psicológicas...)

Factores relacionados con el tratamiento

- Complejidad del régimen de tratamiento (p.ej., múltiples medicaciones)

- Larga duración de la enfermedad

- Grado de cambio comportamental requerido (p.ej., interferencia con patrones de conducta habituales o alteraciones importantes en el estilo de vida)

- Efectos colaterales de la medicación (p.ej., sedación, efectos extrapiramidales)

- Coste

- Preparación, formato del preparado y modo de administración (p.ej., cápsulas, tabletas o inyecciones)

- Color y tamaño de la pastilla

- Etiquetas inadecuadas

- Diseño del recipiente incómodo

Factores relacionados con la institución sanitaria

- Discontinuidad del cuidado

- Prolongado tiempo de espera

- Prolongado lapso de tiempo entre el contacto y la consulta (más de o días)

- Falta de asignación de un tiempo para cada cita

- Falta de cohesión en el sistema de ofrecer el tratamiento

- Inconvenientes asociados al funcionamiento del centro (p.ej., horario, falta de eficacia, personal poco amable, disponibilidad de aparcamiento...)

- Mala reputación sobre las instalaciones o medios para el tratamiento

- Inadecuada supervisión por parte de los profesionales

Factores relacionados con la relación (interacción paciente-profesional de la salud)

- Comunicación inadecuada

- Ausencia de las actitudes y conductas necesarias (verbales y no verbales) por parte del profesional o del paciente

- Dificultad del profesional de la salud para elicitar preocupaciones o sentim. negativos del paciente

- Insatisfacción del paciente

- Supervisión inadecuada

Adaptado de D. Meichenbaum y D. Turk (1991). Cómo facilitar el seguimiento de los tratamientos terapéticos. Bilbao: DDB. 


\section{LA INFECCIÓN POR VIH/SIDA: IMPORTANCIA DE LA ADHESIÓN TERAPÉUTICA Y DIFICULTADES ASOCIADAS}

La infección por VIH/SIDA se ha convertido en las últimas dos décadas en una de las prioridades para los sistemas sanitarios de todo el mundo tanto por su prevalencia (afecta ya a cerca de 40 millones de personas) como por la gravedad de la enfermedad. Desde que se aislara el Virus de Inmunodeficiencia Humana (VIH) a principios de los años 80 se ha invertido una notable cantidad de esfuerzo de los investigadores biomédicos y de dinero procedente de los sectores públicos y privados para poder llegar a comprender cuáles son los mecanismos que hacen tan poderosa a esta enfermedad.

Hoy sabemos muchas cosas de ella. Sabemos, por ejemplo, que el VIH es el responsable de la misma y que este virus se encuentra en todos los fluidos corporales, especialmente en la sangre y el semen o las secreciones vaginales. También conocemos bastante bien cuáles son las conductas de riesgo y las principales vías para la transmisión del VIH, fundamentalmente, la transmisión vertical de la madre al niño durante el embarazo, el parto o la lactancia, la transmisión a través de relaciones sexuales no protegidas, la transmisión a través del intercambio de agujas y jeringas infectadas en el colectivo de toxicómanos, la transmisión ocupacional a través de un pinchazo accidental o contacto con fluidos infectados y la transmisión a través de las transfusiones de sangre, cuyo riesgo en la actualidad es prácticamente nulo. El hecho de que el VIH sea un virus cuyos mecanismos de propagación son fácilmente evitables a través del cambio de hábitos nos ha llevado demasiado ilusamente a pensar que su control era sencillo (Perloff, 2001) pero la experiencia nos ha demostrado que pocas cosas son más difíciles que modificar la conducta humana.
En el ámbito clínico, no ya de la prevención, hemos podido aprender a lo largo de estos años que el VIH, una vez dentro de nuestro organismo, ataca a nuestro sistema inmunitario a través de una de sus células principales, los linfocitos $\mathrm{T} 4$ en los que se multiplica y a los que acaba destruyendo hasta que la función inmune está totalmente debilitada y el enfermo comienza a contraer una gran cantidad de infecciones oportunistas causadas por cualquier tipo de virus, bacteria, hongo, protozoo, etc.

El tratamiento médico de cualquier paciente con infección por VIH/SIDA, en principio, se suele componer de dos partes: por un lado, los fármacos destinados a defender al sistema inmunitario del VIH, los denominados antirretrovirales (el VIH es un retrovirus porque se compone de ARN y no de ADN), incluyendo los Inhibidores de la Transcriptasa Inversa y los Inhibidores de la Proteasa; por otro lado, los fármacos que son necesarios para el tratamiento de cualquiera de las infecciones oportunistas que presenta el paciente que en ocasiones son múltiples.

Sin embargo, esto no ha sido siempre así. En el período inicial de la epidemia del SIDA no existía ningún tratamiento efectivo para la enfermedad. Las intervenciones de los médicos eran, en sus efectos, de tipo paliativo. Se desarrollaron intervenciones dirigidas a tratar y reducir las consecuencias de las enfermedades oportunistas asociadas a la inmunodeficiencia. La siguiente etapa, que podría comprender entre mediados de los 80 y los inicios de la década de los 90, estuvo caracterizada por el desarrollo de los denominados Inhibidores de la Transcriptasa Inversa, enzima responsable de la producción de ADN por parte del VIH, necesario para entrar en el núcleo del linfocito e integrarse en su código genético. Sin embargo, el VIH tiene un ciclo de vida muy corto. $\mathrm{Al}$ menos 10 billones de partículas de VIH son producidas y des- 
truidas diariamente en el organismo y la vida media del VIH es de 6 horas en una persona infectada (Ho, Neumann, Perelson, Chen, Leonard y Markowitz, 1995). Como consecuencia de la extraordinariamente rápida replicación del VIH, el virus muta a gran velocidad y fácilmente se vuelve resistente a las terapias simples. Por ello, las terapias con Inhibidores de la Transcriptasa Inversa, como el AZT o zidovudina, didanosina, estavudina y lamivudina, en un principio, eran capaces de reducir la replicación del virus, pero en poco tiempo, se volvían ineficaces (Kelly, Otto-Salaj, Sikkema, Pinkerton y Bloom, 1998).

Ante esta situación se hacía necesario el desarrollo de nuevos fármacos capaces de reducir drásticamente el número de virus o carga viral para con ello reducir también su capacidad de replicación y de mutación. A mediados de 1996 apareció un nuevo tipo de antirretroviral, los denominados Inhibidores de la Proteasa, enzima responsable de la replicación del virus dentro del linfocito. La inclusión de estos fármacos, entre los que cabe citar el Ritonavir, Indinavir, Nelfinavir y Saquinavir, y más tarde, su combinación con los anteriores dieron lugar a lo que hoy llamamos Terapia Antirretroviral Altamente Activa, conocida más comúnmente con las siglas HAART (Highly Active AntiRetroviral Therapy).

La Terapia Antirretroviral Altamente Activa (HAART) ha demostrado su capacidad para suprimir la carga viral de los pacientes hasta niveles indetectables, incrementar los indicadores de funcionamiento inmunitario tales como el recuento de linfocitos CD4, mejorar el estado clínico de los pacientes y disminuir su mortalidad (Kelly et al., 1998). El cambio en los resultados de los nuevos tratamientos para el VIH ha sido tal que se ha comenzado a hablar desde hace pocos años del SIDA como una enfermedad no necesariamente fatal, sino crónica.
Sin embargo, los nuevos y potentes tratamientos para el SIDA se enfrentan en la actualidad a dos graves problemas. El primero y quizás el más grave es que la revolución que suponen estas nuevas terapias médicas deja al margen al $95 \%$ de los casos que se sitúan en el mundo subdesarrollado o en vías de desarrollo donde la posibilidad de una correcta terapia y cuidados médicos de muy elevado coste es prácticamente nula por motivos económicos (Nájera, 2000). El segundo problema es que los actuales tratamientos contra la infección por VIH conllevan un gran número de pastillas a ingerir diariamente en pautas complejas; se trata de una terapia de larga duración, quizás indefinida; y suele llevar aparejados efectos secundarios de cierta importancia; todo lo cual, puede ayudar a explicar la frecuencia con que los pacientes no se adhieren adecuadamente al tratamiento.

En efecto, aunque pueda parecer contradictorio, a pesar de que el tratamiento contra el SIDA es hoy más efectivo que nunca, son cada vez más los investigadores y clínicos que denuncian los bajos niveles de adhesión terapéutica que presentan estos pacientes (Aversa y Kimberlin, 1996; Ballester, Reinoso, García y Campos, 2000; Chesney, 1997; Gwadz et al., 1999; Ickovics y Meisler, 1997; Kalichman, 1998; López et al., 1999; Samet et al., 1992). La terapia HAART que implica tomarse múltiples fármacos, cada uno con pautas de tratamiento específicas, suele ser más complicada para los pacientes, comparada con las monoterapias, más simples, que solían incluir básicamente AZT antes de 1996 (Catz, Kelly, Bogart, Benotsch y McAuliffe, 2000). Así por ejemplo, los efectos terapéuticos optimos del Indinavir requieren que el fármaco se tome cada 8 horas, el Indinavir debe tomarse con el estómago vacío, al menos dos horas después y una hora antes de las comidas y el Saquinavir debe tomarse con las comidas (Kalichman, 1998). 
Cuando hablamos de adhesión farmacológica, es decir, hasta qué punto los pacientes toman los fármacos prescritos, la mayoría de investigaciones informan de un $50 \%$ de pacientes que no siguen adecuadamente el tratamiento. Pero la adhesión se debe referir también a aspectos como la adopción de medidas preventivas de reinfecciones y la asistencia al régimen de visitas médicas (Holzemer et al., 1999). En este sentido, en nuestro país, López et al. (1999) encuentran que un $56 \%$ de los pacientes no acuden el día programado a las citas con el Servicio de Farmacia, el $10-20 \%$ no acude a las citas programadas con el Servicio de Medicina Interna y el $50 \%$ no toma los fármacos a las horas indicadas. Torres et al. (1999) encuentran un $53 \%$ de pacientes que incumplen el tratamiento. Y más recientemente Ballester et al. (2000) han encontrado que un $53 \%$ de los pacientes con infección por VIH dejan de tomar en ocasiones los fármacos prescritos por el facultativo, el $14 \%$ sigue realizando las mismas prácticas de riesgo que les llevó a la infección por VIH y el $10 \%$ no cumple con el régimen de visitas médicas.

Fuera de nuestras fronteras, Samet et al. (1992) hallaron que aproximadamente un tercio de las personas que toman inhibidores de la transcriptasa inversa interrumpen su consumo, dato que aparece corroborado por los ensayos clínicos de Chesney (1997) e Ickovics y Meisler (1997). Otro tercio parece que puede alterar las pautas del tratamiento intencionadamente (Aversa y Kimberlin, 1996). En el estudio de Gwadz et al. (1999) el porcentaje de no adhesión es del $45 \%$ de los pacientes. Y más recientemente Murphy, Wilson, Durako, Muenz y Belzer (2001) hallaron que tan sólo el $41 \%$ de los adolescentes con VIH presentaban una adhesión plena al tratamiento.

Por lo tanto, sabemos que la falta de adhesión a los tratamientos con antirretrovirales es muy frecuente. A eso hay que añadir la gravedad que en el tratamiento del SIDA incorpora una adhesión inadecuada. La investigación muestra que incluso una moderada o leve falta de adhesión reduce de forma muy importante los beneficios del tratamiento (Catz et al. 2000). Las conductas de riesgo en una persona infectada, cuando le conducen a entrar de nuevo en contacto con el virus, además de incrementarle su carga viral, multiplica las posibilidades de resistencias al tratamiento. Por otro lado, un breve lapso de tiempo sin tomar la medicación puede llevar fácilmente al incremento de la carga viral y la replicación del virus, permitiendo que éste se haga resistente a la medicación (Colven, Harrington, Spach, Cohen y Hooton, 2000). Además, la resistencia a un inhibidor de la proteasa puede tener un efecto negativo en la eficacia de otros inhibidores. Finalmente, la falta de adhesión y la aparición de resistencias ante un fármaco, puede tener a medio plazo efectos sobre la salud pública en general, ya que algunos datos comienzan a confirmar la posibilidad de transmitir a través de las conductas de riesgo cepas de virus resistentes (Quigg et al., 1997), lo que cada vez complicaría más la lucha contra la enfermedad.

La gravedad de los problemas de adhesión al tratamiento en los pacientes con infección por VIH ha hecho que se investiguen los posibles factores relacionados con ellos y su efecto modulador sobre la adhesión (Ballester, Campos, García y Reinoso, 2001). Algunos factores no han mostrado hasta ahora ser excesivamente relevantes, como es el caso de la edad o el sexo (Ballester, García, Reinoso y Campos, en revisión). Sin embargo, distintos estudios han concluido la relevancia que pueden tener algunas variables que presentamos en la Tabla 2 junto con una revisión de las principales investigaciones que han revelado el papel de tales variables sobre la adhesión en pacientes con VIH. Entre los factores que se han visto relacionados con la adhesión se encuen- 
Tabla 2. Revisión de los estudios acerca de los factores relacionados con la adhesión en pacientes con infección por VIH

\begin{tabular}{|c|c|}
\hline $\begin{array}{l}\text { Factores relacionados con la adhesion } \\
\text { en pacientes con infección por VIH }\end{array}$ & Estudios \\
\hline Nivel educativo & Catz, Heckman, Kochman y DiMarco (2001) \\
\hline Creencias culturales del paciente & $\begin{array}{l}\text { Erwin y Peters (1999) } \\
\text { Siegel, Karus y Schrimshaw (2000) }\end{array}$ \\
\hline Valoración de la gravedad de la enfermedad & $\begin{array}{l}\text { Ballester et al. (2000) } \\
\text { Gao, Nau, Rosenbluth, Scott y Woodward (2000) }\end{array}$ \\
\hline Percepción acerca de la eficacia del tratamiento & $\begin{array}{l}\text { Mehta, Moore y Graham (1997) } \\
\text { Ballester et al. (2000) }\end{array}$ \\
\hline Complejidad del tratamiento & $\begin{array}{l}\text { Kastrissios et al. (1998) } \\
\text { Torres et al. (1999) } \\
\text { Murphy, Johnston y Martin (2000) }\end{array}$ \\
\hline Vulnerabilidad percibida & Gao et al. (2000) \\
\hline Intolerancia a los efectos secundarios & $\begin{array}{l}\text { Rabkin y Chesney (1998) } \\
\text { Roca, Gómez y Arnedo (2000) } \\
\text { Catz et al. (2000) }\end{array}$ \\
\hline Creencia acerca de la toxicidad de los fármacos & $\begin{array}{l}\text { Perry, Ryan, Ashman y Jacobsberg (1992) } \\
\text { Smith, Rapkin, Morrison y Kammerman (1997) }\end{array}$ \\
\hline Relación con el facultativo & $\begin{array}{l}\text { Stall et al. (1996) } \\
\text { Gerbert, Love y Caspers (1999) } \\
\text { Gordillo (1999) } \\
\text { Roberts y Volberding (1999) } \\
\text { Ballester et al. (2000) } \\
\text { Murphy et al. (2000) } \\
\text { Catz et al. (2001) } \\
\end{array}$ \\
\hline $\begin{array}{l}\text { Inestabilidad en las vidas de los pacientes } \\
\text { (p.ej., no tener un hogar) }\end{array}$ & $\begin{array}{l}\text { Besch (1995) } \\
\text { Bangsburg, Tulsky, Hecht y Moss (1997) }\end{array}$ \\
\hline Ánimo depresivo & $\begin{array}{l}\text { Singh et al. (1996) } \\
\text { Holzemer et al. (1999) } \\
\text { Gordillo, Del Amo, Soriano y González-Lahoz (1999) } \\
\text { Murphy et al. (2000) } \\
\text { Catz et al. (2000) } \\
\text { Murphy et al. (2001) } \\
\text { Remor, } 2002\end{array}$ \\
\hline Ansiedad & Catz et al. (2001) \\
\hline Problemas psicopatológicos en general & Cohen y Jacobson (2000) \\
\hline Falta de apoyo social & $\begin{array}{l}\text { Catz, McClure, Jones y Brantley (1999) } \\
\text { Catz et al. (2000) } \\
\text { Remor, } 2002\end{array}$ \\
\hline Consumo excesivo de alcohol & $\begin{array}{l}\text { Petry (1999) } \\
\text { Catz et al. (2001) }\end{array}$ \\
\hline Historia de consumo de drogas & $\begin{array}{l}\text { Freeman, Rodriguez y French (1996) } \\
\text { Singh et al. (1996) } \\
\text { Gwadz et al. (1999) } \\
\text { Kaplan et al. (1999) } \\
\text { Gordillo et al. (1999) } \\
\text { Haubrich et al. (1999) } \\
\text { Ballester et al. (2000) } \\
\text { Moatti et al. (2000) } \\
\end{array}$ \\
\hline Olvido & $\begin{array}{l}\text { Hecht (1997) } \\
\text { Chesney et al. }(2000)\end{array}$ \\
\hline
\end{tabular}


tran el nivel educativo, las creencias culturales del paciente, la valoración de la gravedad de la enfermedad, la percepción acerca de la eficacia del tratamiento, la complejidad del tratamiento, la vulnerabilidad percibida, la intolerancia a los efectos secundarios, la creencia acerca de la toxicidad de los fármacos, la relación con el facultativo, la inestabilidad en las vidas de los pacientes (p.ej., no tener un hogar), el ánimo depresivo, la ansiedad, los problemas psicopatológicos en general, la falta de apoyo social, el consumo excesivo de alcohol, la historia de consumo de drogas o simplemente el olvido.

A pesar de todos los estudios mencionados los problemas de adherencia al tratamiento de los pacientes con VIH son $\tan$ frecuentes y tan complejos que ninguna combinación de variables sociodemográficas ha sido capaz de predecir en un alto grado qué pacientes no van a seguir las prescripciones médicas (Wright, 2000). Sin embargo, estamos hablando de un problema cuya solución es de vital importancia dada la existencia en la actualidad de tratamientos de gran eficacia que pueden ayudar a incrementar no sólo la esperanza de vida del paciente, sino también y de manera fundamental, su calidad de vida. Incluso algunos autores como Altice y Friedland (1998) hablan de la etapa actual como la "era de la adhesión» en el tratamiento contra el VIH. De todo ello se deriva la importancia de desarrollar y aplicar programas de probada eficacia para mejorar la adhesión al tratamiento de los pacientes con VIH y SIDA.

PROGRAMAS DE INTERVENCIÓN PARA LA MEJORA DE LA ADHESIÓN AL TRATAMIENTO EN PACIENTES CON INFECCIÓN POR VIH

Dado que la infección por VIH/SIDA constituye una enfermedad bastante reciente (apenas llevamos dos décadas luchando contra ella), los programas de intervención para la mejora de la adhesión terapéutica de estos pacientes son bastante escasos. Además de la corta historia de esta enfermedad desde su aparicion, hay que contar con que realmente, el desarrollo de fármacos antirretrovirales eficaces contra la infección todavía es un hecho más reciente. Así, la combinación de inhibidores de la transcriptasa inversa e inhibidores de la proteasa (HAART), que incrementó bruscamente la esperanza de vida de los pacientes infectados, apenas se remonta a 1996. Como hemos dicho anteriormente, es a partir de este momento cuando la adhesión a un tratamiento que demuestra ser de gran eficacia se convierte en un aspecto de una enorme relevancia (Kelly y Kalichman, 2002).

Sin embargo, a pesar de que la investigación sobre la adhesión en el SIDA es forzosamente escasa, actualmente tenemos suficientes datos para afirmar que estamos ante un fenómeno complejo en el que intervienen multitud de variables. En consecuencia, parece bastante comprensible que el tipo de intervención ideal para la mejora de la adhesión debería ser uno que englobase tanto acciones dirigidas al entorno sanitario, como otras llevadas a cabo con los profesionales que prescriben el tratamiento y con los propios pacientes (Department of Health and Human Services, 1999). Como enfatiza Wright (2000), quizás no sea realista esperar que el $100 \%$ de pacientes se adhieran a los tratamientos antirretrovirales ni a ningún tipo de tratamiento, y por ello, éste debería ser negociado individualmente con cada paciente sobre la base de una relación terapéutica abierta y con la ayuda de intervenciones que se dirijan a distintas dimensiones del problema.

Entre los programas que se han dirigido a intervenir sobre el sistema sanitario algunos han intentado crear unidades de 
atención multidisciplinar más integradas con el fin de mejorar la accesibilidad de los pacientes a los cuidados, establecer un sistema de citas más flexible, facilitar los mecanismos para que de forma rápida el paciente puede informar de los efectos secundarios de la medicación y se le pueda dar solución inmediata a sus problemas, o minimizar las barreras de acceso a la medicación, entre otras acciones (Kelly et al. 1998).

Otros programas dirigidos a enfermos con VIH y con otro tipo de enfermedades se han centrado más en las habilidades de comunicación de los profesionales sanitarios con acciones como clarificar a los pacientes los beneficios que pueden esperar del tratamiento (Geletko, Ballard y Matthews, 1995; Muma, Ross, Parcel y Pollard, 1995), implicar al paciente de forma activa en el proceso de toma de decisiones relativas al tratamiento (Catt, Stygall y Catalan, 1995), crear mecanismos que aseguren un contacto frecuente, seguimiento cercano y apoyo intenso entre pacientes y profesionales (Morse et al., 1991), proporcionar información verbal y escrita clara con una retroalimentación y supervisión continuada que garantice la comprensión por parte de los pacientes de las condiciones y exigencias del tratamiento (Becker y Maiman, 1980), y una retroalimentación frecuente al paciente mostrándole el éxito del tratamiento (Kinzie, Leung, Boehnlein y Fleck, 1987). Algunos estudios como el de Gerbert, Bronstone, Clanon, Abercrombie y Bangsberg (2000) muestran que los mismos médicos reconocen sentirse poco preparados para ayudar al paciente a comenzar la terapia antirretroviral y para promover su adhesión al tratamiento. Por ello, autores como Meystre, Dubois, Cochand y Telenti (2000), han insistido en la importancia de entrenar a los profesionales sanitarios en habilidades de comunicación para ser capaces de elicitar los problemas y las interferencias que el paciente padece en su vida cotidiana a causa de la medicación antirretroviral, y los temores asociados como la desconfianza con el tratamiento o el miedo a ser reconocido como enfermo con SIDA a través del mismo.

Finalmente, dentro de los programas de intervención también se han incorporado componentes terapéuticos dirigidos a los aspectos relacionados con el paciente que han mostrado ser eficaces para mejorar la adhesión de los pacientes con VIH a las terapias combinadas de antirretrovirales (Sikkema y Kelly, 1996). Entre las acciones incluidas en estos programas se encuentran: el ajuste de los regímenes de tratamiento al funcionamiento cotidiano del paciente, entrenamiento en solución de problemas, enseñar a los pacientes a superar las barreras potenciales para seguir el tratamiento, establecimiento de metas en áreas relacionadas con la adhesión, entrenamiento en habilidades asociadas a la adhesión, refuerzo a los pacientes por sus esfuerzos para seguir el tratamiento adecuadamente, y el uso de estrategias tecnológicas y de autocontrol para seguir las pautas (dosis y horarios) correctas del tratamiento, tales como los pastilleros o "avisadores» electrónicos de que el paciente debe tomar la medicación (Kelly et al. 1998).

Sin embargo, dada la situación de muchos de los pacientes afectados por esta enfermedad, parece claro que este tipo de intervenciones, para alcanzar una optima eficacia, deberían combinarse con otras que estuvieran enfocadas al tratamiento de los problemas de adicción que algunos enfermos mantienen, el malestar psicológico, las dificultades para afrontar la enfermedad, la inestabilidad en la vida de muchos pacientes e incluso, en algunos casos, la falta de un hogar o de un refrigerador donde guardar algunas de las medicaciones. En este sentido, como señalan Williams y Boykin (1999), los trabajadores sociales también podrían, 
con su actuación, ser importantes agentes para mejorar la adhesión al tratamiento de los pacientes. Según Hecht (1997), un programa ideal para mejorar esta adhesión debería incluir entre sus componentes la clarificación de las instrucciones del tratamiento, la anticipación de los efectos secundarios, la adaptación del régimen de tratamiento al estilo de vida del paciente, la preparación para los cambios en las rutinas cotidianas como pueden ser unas vacaciones y la simplificación del régimen de tratamiento, pero también otros componentes dirigidos a incrementar la motivación del paciente y a tratar problemas indirectos como la depresión, el abuso de sustancias o la relación con los profesionales sanitarios. Por otra parte, un estudio reciente de Paterson et al. (2000), además de encontrar una gran correlación existente entre la adhesión terapéutica a los inhibidores de la proteasa y los resultados clínicos, concluyen que la existencia de perturbaciones emocionales constituyen un factor de riesgo por sí solo para una baja adhesión terapéutica y que, por lo tanto, debe ser una prioridad de los clínicos la detección y tratamiento de los problemas psicopatológicos de los pacientes.

Por ello, algunos autores, han desarrollado programas de tratamiento (ver Tabla 3) que más que estar exclusivamente orientados a la promoción de la adhesión, intentan tomar en consideración otras variables que pueden estar afectándola directa o indirectamente. Se trata de programas para mejorar el afrontamiento de la enfermedad. En este sentido se ha enfatizado la utilidad que podrían tener técnicas de intervención que ayuden al paciente a reducir su ansiedad, su malestar emocional, su sensación de indefensión y la percepción de falta de control. Incluiríamos entre esas técnicas, el entrenamiento en relajación, la terapia cognitiva, la imaginación guiada, el entrena- miento en habilidades de afrontamiento o el entrenamiento asertivo para mejorar la relación con los profesionales sanitarios (Kelly y Murphy, 1992; Besch, 1995). Kalichman (1998) añade a estas técnicas la utilidad de los grupos de apoyo para mejorar la adhesión de los pacientes.

Un ejemplo de estos programas es el de Roteram y Miller (1998) quienes desarrollaron un programa de intervención de tres módulos para jóvenes con $\mathrm{VIH}$, que incluía: (1) hábitos de salud y adhesión terapéutica; (2) conductas sexuales más seguras y abstinencia del uso de sustancias; y (3) calidad de vida. El programa se aplicaba en grupo durante 8-12 sesiones de 2 horas de duración, y estaba pensado especialmente útil para jóvenes con importantes problemas psicosociales.

Sin embargo, hay que reconocer que hasta el momento, los estudios en los que se evalúa la eficacia de estos programas son muy escasos, aunque hay que decir que también lo son los trabajos que evalúan la eficacia de programas para mejorar la adhesión en otras enfermedades, como lo muestra la revisión de Haynes, McKibbon y Kanani (1996). Podemos apenas mencionar unos pocos de estos estudios referidos al SIDA. Por ejemplo, Coates y McKusick (1987) hallaron que tras la aplicación de un programa grupal de entrenamiento en técnicas de manejo del estrés, los pacientes con VIH mostraban menor estrés, depresión y menor frecuencia en las conductas de riesgo que los pacientes del grupo control. En un trabajo publicado por estos autores dos años más tarde (Coates, McKusick, Kuno y Stites, 1989), describían una terapia de grupo que consistía en ocho sesiones (una a la semana) de dos horas de duración cada una de ellas en las que se enfatizaba el entrenamiento en relajación, el cambio de hábitos de salud como la reducción del consumo de tabaco y alcohol y el incremento del descanso y del ejercicio físico, así como otras habilidades para el mane- 
jo del estrés. El resultado de la terapia grupal fue la mejoría en distintas variables clínicas relacionadas con el estrés y el estado emocional de los pacientes.

Emmot (1991), por su parte, evaluó la eficacia de un programa de intervención grupal para pacientes con VIH encontrando que tras el programa había un descenso del ánimo depresivo y de la ansiedad, aunque no cambiaban las habilidades para afrontar la enfermedad. También Folkman et al. (1991) encontraron una mejora en los estilos de afrontamiento, menor autoinculpación y menor depresión tras una terapia grupal aplicada a hombres homosexuales.

En el mismo año, Antoni et al. (1991), aplicaron un programa cognitivo-comportamental a hombres homosexuales antes de la notificación del resultado de las pruebas de anticuerpos. El programa incluía entre sus componentes, técnicas para el manejo del estrés, entrenamiento en relajación, habilidades de afrontamiento de estresores ambientales, valoración del estrés, afrontamiento activo, incremento de la autoeficacia y aumento de las relaciones sociales. Los resultados mostraban que los pacientes que habían recibido el tratamiento mostraban menor depresión y mayor ajuste y sensación de control tras el conocimiento del diagnóstico.

Kelly et al. (1993) evaluaron la eficacia de un programa grupal para pacientes con depresión. Asignaron aleatoriamente 68 hombres seropositivos con una alta puntuación en depresión a uno de tres grupos experimentales. El primero consistía en un tratamiento grupal cognitivo-conductual que incluía estrategias para reducir la ansiedad y la depresión como la reestructuración cognitiva, la relajación muscular, la autorrevelación sobre la enfermedad, la adopción de medidas de sexo seguro y el establecimiento de una red social de apoyo; el segundo era un grupo de apoyo; y el tercero consistía en psicoterapia individual. Los resultados mostraron que ambos tratamientos grupales producían una mejoría en los pacientes significativamente mayor que la terapia individual. En el seguimiento realizado a los tres meses, los pacientes que se encontraban mejor eran los que habían estado en el grupo de apoyo. Sin embargo, los que habían recibido la terapia cognitiva en grupo eran los que más habían reducido su consumo de sustancias.

Por su parte, Eller (1995) evaluó la eficacia de dos técnicas de reducción del estrés en pacientes seropositivos: la relajación muscular y la imaginación guiada. El tratamiento era muy breve en ambos casos. La imaginación guiada consistía en una grabación de 21 minutos que se usaba durante un período de 6 semanas; y la relajación también consistía en una grabación de 12 minutos que se utilizaba durante el mismo período de tiempo. A pesar de la brevedad de la intervención, ambos tratamientos mejoraron a los pacientes más que la condición control en que no se recibía ninguna técnica.

También Lutgendorf et al. (1997) aplicaron un tratamiento de 10 sesiones de 90 minutos de duración en el que se entrenaba a pacientes homosexuales en técnicas de manejo del estrés y se comparaba los resultados frente a un grupo control. Los resultados indicaron que los pacientes que habían recibido el tratamiento experimentaban una reducción de la ansiedad y la disforia, especialmente los que ya partían de niveles bajos de depresión. Además, se evidenciaron algunos efectos positivos del tratamiento sobre el sistema inmunitario de los pacientes.

Más recientemente, McPherson et al. (2000), evaluaron la eficacia de técnicas de consejo breve dirigidas especificamente a la mejora de la adherencia al tratamiento antirretroviral en comparación con un grupo control en el que no se hacía ningún tipo de intervención, obteniendo resultados significativos en la línea de una mayor adhesión terapéutica, 
menos infecciones oportunistas y menos ingresos entre los que recibieron la intervención. Sin embargo, Sorensen et al. (1998) unos años antes, habían comparado la eficacia del consejo breve en el mismo servicio donde se dispensaba la medicación para motivar la adhesión en pacientes con VIH que asistían a programas de metadona con la eficacia de un entrenamiento en solución de problemas para ayudar a los pacientes a superar las barreras a la adhesión. El consejo breve mejoraba la adhesión pero, sin embargo, sus efectos duraban poco tiempo.

En definitiva, los escasos datos que tenemos hasta el momento acerca del desarrollo de programas de intervención para los pacientes con infección por VIH, así como de su eficacia nos permiten extraer las siguientes conclusiones:

(1) En primer lugar, parece difícil desarrollar la intervención ideal en la que estén implicados equipos interdisciplinares bien coordinados y que se dirijan a intervenir tanto en los aspectos relacionados con el sistema sanitario como en los profesionales sanitarios y en el propio paciente. Los programas desarrollados hasta ahora están centrados en alguno de estos ámbitos, aunque todos los autores des-

Tabla 3. Revisión de los componentes terapéuticos de algunos programas de intervención para pacientes con infección por VIH/SIDA

\begin{tabular}{cl}
\hline \multicolumn{1}{c}{ Autores } & \multicolumn{1}{c}{ Tratamiento } \\
\hline Coates y McKusick (1987) & $\begin{array}{l}\text { Programa grupal de entrenamiento en técnicas de manejo del } \\
\text { estrés. }\end{array}$ \\
\hline
\end{tabular}

Coates, McKusick, Kuno y Stites (1989) Terapia de grupo (ocho sesiones de dos horas de duración cada una) en las que se enfatizaba el entrenamiento en relajación, el cambio de hábitos de salud como la reducción del consumo de tabaco y alcohol y el incremento del descanso y del ejercicio físico, así como otras habilidades para el manejo del estrés.

Antoni et al. (1991)

Técnicas para el manejo del estrés, entrenamiento en relajación, habilidades de afrontamiento de estresores ambientales, valoración del estrés, afrontamiento activo, incremento de la autoeficacia y aumento de las relaciones sociales.

Kelly et al. (1993)

Terapia grupal cognitivo-conductual que inclura estrategias para reducir la ansiedad y la depresión como la reestructuración cognitiva, la relajación muscular, la autorrevelación sobre la enfermedad, la adopción de medidas de sexo seguro y el establecimiento de una red social de apoyo.

Eller (1995)

Aplicación individual de la relajación muscular y la imaginación guiada a través de grabaciones.

Lutgendorf et al. (1997)

Terapia (10 sesiones de $90 \mathrm{~min}$. de duración) en la que se entrenaba a pacientes homosexuales en técnicas de manejo del estrés

Sorensen et al. (1998) Entrenamiento en solución de problemas

Roteram y Miller (1998)

Programa de intervención de tres módulos para jóvenes con VIH, que incluía hábitos de salud y adhesión terapéutica; conductas sexuales más seguras y abstinencia del uso de sustancias; y calidad de vida. El programa se aplicaba en grupo durante 8-12 sesiones de 2 horas de duración. 
tacan lo importante que sería intervenir desde las diferentes perspectivas y además, a ser posible, antes del inicio del tratamiento antirretroviral.

(2) En segundo lugar, y en la misma línea, parece que no resulta demasiado útil la aplicación de programas de intervención centrados en aspectos demasiado concretos, como puede ser el uso de pastilleros, que no tengan en cuenta la complejidad de la situación del paciente en toda su globalidad.

(3) En tercer lugar, los escasos estudios realizados hasta ahora no nos permiten concluir que ninguna técnica de intervención sea más eficaz que otra para la mejoría de los pacientes con VIH. Quizás en los próximos años debería profundizarse más en esa línea de investigación, ya que, si son escasos los programas de tratamiento desarrollados para los enfermos con VIH, todavía lo son más los estudios controlados acerca de su eficacia y más aún el análisis de la eficacia diferencial de cada una de las técnicas que componen tales programas.

(4) En cuarto lugar, también sabemos, aunque hacen falta más estudios al respecto, que la intervención grupal es más eficaz que la intervención individual en estos pacientes.

(5) Finalmente, podemos afirmar que es mejor cualquier intervención que ninguna y que urge el desarrollo de nuevos programas que aborden la problemática de estos pacientes desde un enfoque integral.

\section{REFERENCIAS BIBLIOGRÁFICAS}

Altice, F., y Friedland, G. (1998). The Era of Adherence to HIV Therapy. Annals of Internal Medicine, 129, 503-504.

Antoni, M., Baggett, L., Ironson, G., LaPerriere, A., August, S., Klimas, N., Schneiderman, N., y Fletcher, M. (1991). Cognitive- behavioral stress management intervention buffers distress responses and immunologic changes following notification of HIV1 seropositivity. Journal of Consulting and Clinical Psychology, 59, 906-915.

Aversa, S.L., y Kimberlin, C. (1996). Psychosocial aspects of antiretroviral medication use among HIV patients. Patient Education and Counselling, 29, 207-219.

Ballester, R. (1993a). Conducta de Enfermedad: la búsqueda de una identidad. Boletín de Psicología, 38, 63-88.

Ballester, R. (1993b). Un análisis crítico de la aportación de Parsons a la Psicología de la Salud. Cuadernos de Medicina Psicosomática, 25, 41-51.

Ballester, R. (1998). Introducción a la Psicología de la Salud. Valencia: Promolibro.

Ballester, R., Campos, A., García, S., y Reinoso, I. (2001). Variables moduladoras de la adherencia al tratamiento en pacientes con Infección por VIH. Psicología Conductual, 9, 299-322.

Ballester, R., García, S., Reinoso, 1., y Campos, A. (en revision). Gender differences in adherence to treatment and illness behaviour in HIV/AIDS patients: an exploratory study in Spain. International Journal of Psychology.

Ballester, R., Reinoso, I., García, S., y Campos, A. (2000). Adherencia al tratamiento en la infección por VIH. Análisis y Modificación de Conducta, 109, 689-718.

Bangsburg, D., Tulsky, J.P, Hecht, F.M., y Moss, A.R. (1997). Protease inhibitors in the Homeless. Journal of the American Medical Association, 278, 63-65.

Barofsky, I. (1977). Medication noncompliance. Thorofare, N.J.: Slack.

Becker, M., y Maiman, L. (1980). Strategies for enhancing patient compliance. Journal of Community Health, 6, 113-115.

Besch, C.L. (1995). Compliance in clinical trials. AIDS, 9, 1-10.

Blackwell, B. (1972). The drug defaulter. Clinical Pharmacology Therapy, 13, 841-848.

Blackwell, B. (1973). Drug therapy: patient compliance. New England Journal of Medicine, 289, 245-251.

Blackwell, B. (1979). Treatment adherence: a contemporary viewpoint. Psychosomatics, 20, 27-35. 
Buchman, W.F. (1997). Adherence: a matter of self-efficacy and power. Journal of Advanced Nursery.

Cameron, C. (1996). Patient compliance: recognition of factors involved and suggestions for promoting compliance with therapeutic regimens. Journal of Advanced Nursing, 24, 244-250.

Catt, A., Stygall, J., y Catalan, J. (1995). Acceptance of zidovudine (AZT) in early HIV disease: the role of health beliefs. AIDS Care, 229-235.

Catz, S., Heckman, T., Kochman, A., y DiMarco, M. (2001). Rates and correlates of HIV treatment adherence among late middleaged and older adults living with HIV disease. Psychology, Health and Medicine, 6, 47-58.

Catz, S., Kelly, J., Bogart, L., Benotsch, E., y McAuliffe, T. (2000). Patterns, correlates and barriers to medication adherence among persons prescribed new treatments for HIV disease. Health Psychology, 19, 124-133.

Catz, S., McClure, J., Jones, G., y Brantley, P. (1999). Predictors of outpatient medical appointment attendance among persons with HIV. AIDS Care, 11, 361-373.

Chesney, M., Ickovics, J., Chambers, D., Gifford, A., Neidig, J., Zwickl, B., y Wu, A. (2000). Self-reported adherence to antiretroviral medications among participants in HIV clinical trials: The AACTG Adherence Instruments. AIDS Care, 12, 255-266.

Chesney, M.A. (1997). New antiretroviral therapies: adherence challenges and strategies. Evolving HIV treatments: Advances and the challenge of adherence, $37^{\text {th }} I C A$ $A C$ Symposium, Toronto, Canada, September.

Coates, T., y McKusick, L (1987, Junio). The efficacy of stress management in reducing high risk behavior and improving immune function in HIV antibody positive men. Paper presented at the Third International Conference on AIDS, Washington, D.C.

Coates, T., McKusick, L., Kuno, R., y Stites, D. (1989). Stress reduction training changed number of sexual partners but not immune function in men with HIV. American Journal of Public Health, 79, 885-886.
Cohen, M., y Jacobson, J. (2000). Maximizing life's potentials in AIDS: A psychopharmacologic update. General Hospital Psychiatry, 22, 375-388.

Cohen, S. (Ed.) (1979). New directions in patient compliance. Lexington: Lexington Books.

Colven, R., Harrington, R., Spach, D., Cohen, C., y Hooton, T. (2000). Retroviral rebound Syndrome after cessation of suppressive antiretroviral therapy in three patients with chronic HIV infection. Annals of Internal Medicine, 133, 430-434.

Davidson, P. (1976). Therapeutic compliance. Canadian Psychological Review, 17, 247259.

Davidson, P. (1982). Issues in patient compliance. En T. Millon, C. Green y R. Meagher, Handbook of Clinical Health Psychology (pp. 417-434). Plenum Press: New York.

Davis, M.S. (1966). Variations in patient's compliance with doctor's advice: analysis of congruence between survey responses and results of empirical observations. Journal of Medical Education, 41, 1037-1048.

Department of Health and Human Services (1999). Guidelines for the use of antiretrovirals agents in HIV-infected adults and adolescents (The Living Document, 5 mayo): http://www.hivatis.org/atisnew.html

Díaz-Plaja, F. (1996). El médico en las letras españolas. Barcelona: Ediciones $\mathrm{B}$.

DiMatteo M., y DiNicola, D. (1982). Achieving patient compliance: The Psychology of the medical practitioner's role. New York: Pergamon Press.

DiMatteo, M.R. (1979). A social psychological analysis of patient-physician rapport: toward a science of the art of medicine. Journal of Social Issues, 35, 12-33.

DiMatteo, M.R. (1994). Enhancing patient adherence to medical recommendations. Journal of the American Medical Association, 271, 79-83.

Dunbar J.M., y Agras, W.S. (1980). Compliance with medical instructions. En J.M. Ferguson y C.B. Taylor, Comprehensive handbook of behavioral medicine (Vol. 3). New York: Spectrum.

Eisenthal, S., Emery, R., Lazare, A., y Udin, H. (1979). Adherence and the negotiated 
approach to patienthood. Archives of General Psychiatry, 36, 393-398.

Elder, R.G. (1963). What is the patient saying? Nurs. Forum, 2, 25-37.

Eller, L. (1995). Effects of two cognitive-behavioral interventions on immunity and symptoms in persons with HIV. Annals of Behavioral Medicine, 17, 339-348.

Emmott, S. (1991, Junio). Cognitive group therapy for coping with HIV Infection. Paper presented at the Seventh International Conference on AIDS, Florencia (Italia)

Engel, G. (1977). The need for a new medical model: a challenge for biomedicine. Science, 196, 129-136.

Engel, G.L. (1962). A unified concept of health and disease. En G.L. Engel, Psychological Development in Health and Disease. Philadelphia: Saunders.

Erwin, J., y Peters, B. (1999). Treatment issues for HIV+ Africans in London. Social Science and Medicine, 49, 1519-1528.

Folkman, S., Chesney, M., McKusick, L., Ironson, G., Johnson, D., y Coates, T. (1991). Translating coping theory into an intervention. En J. Eckenrode (Ed.), The Social Context of Stress. Nueva York: Plenum Press.

Freeman, R., Rodriguez, G., y French, J. (1996). Compliance with AZT treatment regimen of HIV-seropositive injection drug users: A neglected issue. AIDS Education and Prevention, 8, 58-71.

Friedman, I., y Litt, I. (1986). Promoting adolescent's compliance with therapeutic regimens. Prevention in Primary Care, 33, 955972.

Gao, X., Nau, D., Rosenbluth, S., Scott, V., y Woodward, C. (2000). The relationship of disease severity, health beliefs and medication adherence among HIV patients. AIDS Care, 12, 387-398.

Geletko, S., Ballard, C., y Matthews, W. (1995). Health beliefs and discontinuation of zidovudine therapy. American Journal of Health System Pharmacy, 52, 505-507.

Gerber K., y Nehemkis, A. (Eds.) (1986). Compliance: the dilemma of the chronically ill. New York: Springer.

Gerbert, B., Bronstone, A., Clanon, K., Abercrombie, P., y Bangsberg,D. (2000). Combination antiretroviral therapy: Health care providers confront emerging dilemmas. AIDS Care, 12, 409-421.

Gerbert, B., Love, C., y Caspers, N. (1999). Making all the Difference in the World: How physicians can help HIV-seropositive patients become more involved in their health care. AIDS Patient Care and STDS, 13, 29-39.

Gordillo, M.V., Del Amo, J., Soriano, V., y González-Lahoz, J. (1999). Sociodemographic and psychological variables influencing adherence to antiretroviral therapy. AIDS, 13, 1763-1769.

Gordillo, M.V. (1999). Variables psicológicas que influyen en la adherencia al tratamiento antirretrovírico. V Congreso Nacional sobre el SIDA. Santiago de Compostela: 13-16 Abril. Publicación Oficial de la Sociedad Española Interdisciplinaria del SIDA, 10, supl. 1, pp. 166-167.

Gwadz, M., De-Vogli, R., Rotheram-Borus, M.J., Diaz, M., Cisek, T., James, N., y Tottenham, N. (1999). Behavioral practices regarding combination therapies for HIV/AIDS. Journal of Sex Education and Therapy, 1-2, 81-88.

Haney, C.A. (1971). Psychosocial factors involved in medical decision making. En R. Coombs y C. Vincent (Eds.), Psychosocial aspects of medical training. Springfield: C.C. Thomas.

Haubrich, R., Little, S., Currier, J., Forthal, D., Kemper, C., Beall, G., Johnson, D., Dube, M., Hwang, J., y McCutchan, J. (1999). The value of patient-reported adherence to antiretroviral therapy in predicting virologic and immunologic response. AIDS, 13, 1099-1107.

Haynes, R., McKibbon, K., y Kanani, R. (1996). Systematic review of randomised trials of interventions to assist patients to follow prescriptions for medications. Lancet, 348, 383-386.

Hecht, F.M. (1997, December). Adherence to HIV treatment. Paper presented at the meeting of Clinical Care of the AIDS Patients, San Francisco, California.

Ho, D., Neumann, A., Perelson, A., Chen, W., Leonard, J., y Markowitz, M. (1995). Rapid turnover of plasma virions and CD4 lymphocytes in HIV-1 infection. Nature, 373, 123-126. 
Holzemer, W., Corless, I., Nokes, K., Turner, J., Brown, M., Powell-Cope, G., Inouye, J., Henry, S., Nicholas, P., y Portillo, C. (1999). Predictors of Self-Reported Adherence in Persons living with HIV-disease. Patient Care and STDS, 13, 185-197.

Ickovics, J., y Meisler, A.W. (1997). Adherence in AIDS clinical trials: a framework for clinical research and clinical care. Journal of Clinical Epidemiology, 50, 385-391.

Kalichman, S.C. (1998). Understanding AIDS: Advances in Research and Treatment. Washington: American Psychological Association.

Kaplan, J., Parham, D., Soto-Torres, L., van Dyck, K., Greaves, J., Rauch, K., Ellis, B., y Amandus, H. (1999). Adherence to guidelines for antiretroviral therapy and for preventing opportunistic infections in HIVinfected adults and adolescents in Ryan White-funded facilities in the United States. Journal of Acquired Inmune Deficiency Syndrome, 3, 228-235.

Kasl, S. (1975). Issues in patient adherence to health care regimens. Journal of Human Stress, 1, 5-18.

Kastrissios, H., Suárez, J.R., Katzenstein, D., Girard, P., Sheiner, L., y Blaschke, T. (1998). Characterizing patterns of drugtaking behavior with a multiple drug regimen in an AIDS clinical trial. AIDS, 17, 2295-2303.

Kelly, J., y Murphy, D. (1992). Psychological interventions with AIDS and HIV: prevention and treatment. Journal of Consulting and Clinical Psychology, 60, 576-585.

Kelly, J., Murphy, D., Bahr, G., Kalichman, S., Morgan, M., Stevenson, L., Koob, J., Brasfield, T., y Bernstein, B. (1993). Outcome of cognitive-behavioral and support group brief therapies for depressed persons diagnosed with HIV infection. American Journal of Psychiatry, 150, 1679-1680.

Kelly, J., Otto-Salaj, L., Sikkema, K., Pinkerton, S., y Bloom, F. (1998). Implications of HIV Treatments Advances for Behavioral Research on AIDS: Protease Inhibitors and new challenges in HIV secondary prevention. Health Psychology, 17, 310-319.

Kelly, J.A., y Kalichman, S. (2002). Behavioral research in HIV/AIDS primary and secondary prevention: recent advances and future directions. Journal of Consulting and Clinical Psychology, 70, 629-639.

Kinzie, J., Leung, P., Boehnlein, J., y Fleck, J. (1987). Antidepressant blood levels in Southeast Asians: clinical and cultural implications. Journal of Nervous and Mental Diseases, 175, 480-485.

Kirscht, J., y Rosenstock, I. (1979). Patients`s problems in following recommendations of health experts. En G. Stone, F. Cohen y N. Adler, Health Psychology. San Francisco: Jossey-Bass.

Kristeller, J., y Rodin, J. (1984). The function of attention in cognitive models of behavior change and maintenance. En A. Baum, S. Taylor y J. Singer (Eds.), Handbook of Psychology and Health (Vol. 4). Hillsdale: Erlbaum.

Lederer, H.D. (1952). How the sick view their world. Journal of Social Issues, 8, 4-15.

López, A., Juega, J., Baliñas, J., Pita, S., Margusino, L., Picallos, M., Pedreira, J.D. (1999). Cumplimiento terapéutico en pacientes VIH+. Publicación Oficial de la Sociedad Española Interdisciplinaria del SIDA, 10, supl. 1, 43.

Lutgendorf, S., Antoni, M., Ironson, G., Klimas, N., Kumar, M., Starr, K., McCabe, P., Cleven, K., Fletcher, M., y Schneiderman, N. (1997). Cognitive-behavioral stress management decreases dysphoric mood and herpes simplex virus-type 2 antibody titers in symptomatic HIV-seropositive gay men. Journal of Consulting and Clinical Psychology, 65, 31-43.

McPherson, S., Malow, R., Penedo, F., Jones, D., Schneiderman, N., y Klimas, N. (2000). Enhancing adherence to combination antiretroviral therapy in non-adherent HIVpositive men. AIDS Care, 12, 399-404.

Mechanic, D. (1962). The concept of Illness Behavior. Journal of Chronical Diseases, 15, 189-194.

Mehta, S., Moore, R. D., \&Graham, N. M. H. (1997). Potential factors affecting adherence with HIV therapy. AIDS, 11, 1665-1670.

Meichenbaum, D., y Turk, D. (1991) (Original en 1987). Cómo facilitar el seguimiento de los tratamientos terapéuticos: Guía práctica para los profesionales de la salud. Bilbao: DDB.

Meystre, G., Dubois, F., Cochand, P., y Telenti, A. (2000). Antiretroviral therapies from 
the patient's perspective. AIDS Care, 12, 717-721.

Millon. T. (1975). Medical Behavioral Science. Philadelphia: Saunders.

Moatti, J., Carrieri, M., Spire, B., Gastaut, J., Cassuto, J., y Moreau, J. (2000). Adherence to HAART in French HIV-infected injecting drug users: the contribution of buprenorphine drug maintenance treatment. The Manif 2000 study group. AIDS, 14, 151-155.

Morales, J.F. (1985). La relación profesional de la salud-enfermo. En J.F. Morales, A. Blanco, C. Huici y J.M. Fernández-Dols (Comps.), Psicología Social Aplicada. Bilbao: Desclée de Brouwer.

Morisky, D., Green, L., y Levine, D. (1986). Concurrent and predictive validity of a self-reported measure of medication adherence. Medical Care, 24, 67-74.

Morse, E., Simon, P., Coburn, M., Hyslop, N., Greenspan, D., y Balson, P. (1991). Determinants of subject compliance within an experimental anti-HIV drug protocol. Social Science and Medicine, 32, 11611167.

Muma, R., Ross, M., Parcel, G., y Pollard, R. (1995). Zidovudine adherence among individual with $\mathrm{HIV}$ infection. AIDS Care, 7, 439-447.

Murphy, D., Johnston, K., y Martin, D. (2000). Barriers to Antiretroviral Adherence among HIV-Infected Adults. AIDS Patient Care and STDs, 14, 47-58.

Murphy, D., Wilson, C., Durako, S., Muenz, L., y Belzer, M. (2001). Antiretroviral medication adherence among the REACH HIVinfected adolescent cohort in the USA. AIDS Care, 13, 27-40.

Nájera, R. (2000). Origen, situación actual y tendencias de la epidemia del VIH/SIDA. Publicación Oficial de la SEISIDA, 11, 361363.

Ong, L.M., Haes, J.C., Hoos, A.M., y Lammes, F.B. (1995). Doctor-patient communication: a review of the literature. Social Science and Medicine, 40, 903-918.

Parsons, T. (1951). The Social System. Glencoe: The Free Press.

Paterson, D., Swindells, S., Mohr, J., Brester, M., Vergis, E., Squier, C., Wagener, M y Singh, N. (2000). Adherence to protease inhibitor therapy and outcomes in patients with HIV infection. Annals of Internal Medicine, 133, 21-30

Perloff, R.M. (2001). Persuading people to have safer sex. New Jersey: Lawrence Erlbaum Associates

Perry, S., Ryan, J., Ashman, T., y Jacobsberg, L. (1992). Refusal of zidovudine by HIVpositive patients. AIDS, 6, 514-515.

Petry, N. (1999). Alcohol use in HIV patients: What we don't know may hurt us. International Journal of STD and AIDS, 19, 561570.

Quigg, M., Rebus, S., France, A., McMenamin, J., Darby, G., y Leigh-Brown, A. (1997). Mutations associated with zidovudine resistance in HIV-1 among recent seroconverters. AIDS, 11, 835-836.

Rabkin, J. G., y Chesney, M. (1998). Treatment adherence to HIV medications: The Achilles heel of the new therapeutics. En D. Ostrow \& S. Kalichman (Eds.), Behavioral and mental health impacts of new HIV therapies. New York: Plenum Press.

Remor, E. (2002). Valoración de la adhesión al tratamiento antirretroviral en pacientes VIH+. Psicothema, 14, 262-267.

Roberts, K., y Volberding, P. (1999). Adherence communication: a qualitative analysis of physician-patient dialogue. AIDS, 13, 1771-1778.

Roca, B., Gómez, C., y Arnedo, A. (2000). A randomized, comparative study of lamivudine plus stavudine, with indinavir or nelfinavir, in treatment-experienced HIVinfected patients. AIDS, 14, 157-161.

Roteram, B., y Miller, S. (1998). Secondary prevention for youths living with HIV. AIDS Care, 10, 17-34.

Roth, H. (1987). Measurement of compliance. Patient education and counselling, 10, 107-116

Rotter D.L., y Hall, J.A. (1992). Doctor talking with patients, patients talking with doctors. Westport: Auburn House.

Samet, J.H., Libman, H., Steger, K.A., Dhwan, R.K., Chen, J., Shevitz, A.H., Dewees-Dunk, R., Leveson, S., Kufe, D., y Caven, D.E. (1992). Compliance with zidovudine therapy in patients infected with HIVtype 1: A cross sectional study in a municipal hospital clinic. American Journal of Medicine, 92, 495-502. 
Samet, J., Sullivan, L., Traphagen, E., e Ickovics, J. (2001). Measuring adherence among HIV-infected persons: Is MEMS consummate technology? AIDS and Behavior, 5, 21-30.

Siegel, K., Karus, D., y Schrimshaw, E. (2000). Racial differences in attitudes toward protease inhibitors among older HIV-infected men. AIDS-Care, 12, 423-434.

Sikkema, K., y Kelly, J. (1996). Behavioral medicine interventions can improve the quality of life and health of persons with HIV disease. Annals of Behavioral Medicine, 18, 40-48.

Singh, N., Squier, C., Sivek, C., Wagener, M., Nguyen, M.H., y Yu, V.L. (1996). Determinants of compliance with antiretroviral therapy in patients with human immunodeficiency virus: Prospective assessment with implications for enhancing compliance. AIDS Care, 8, 261-269.

Smith, M., Rapkin, B., Morrison, A., y Kammerman, S. (1997). Zidovudine adherence in persons with AIDS. The relation of patient beliefs about medication to self-termination of therapy. Journal of General Internal Medicine, 12, 216-223.

Sorensen, J., Mascovich, A., Wall, T., DePhilippis, D., Batki, S., y Chesney, M. (1998). Medication adherence strategies for drug abusers with HIV/AIDS. AIDS Care, 10, 297-312.

Stall, R., Hoff, C., Coates, T.J., Paul, J., Phillips, K.A., Estrand, M., Kegeles, S., Catania, J., Daigle, D., y Diaz, R. (1996). Decisions to get HIV tested and to accept antiretroviral therapies among gay/bisexual men: Implications for secondary prevention efforts. Journal of Acquired Immu- ne Deficiency Syndromes and Human Retrovirology, 11, 151-160.

Stone, G.C. (1979). Patient compliance and the role of the expert. Journal of Social Issues, 35, 34-54.

Stone, G.C., Cohen, F., y Adler, N. (1979). Health Psychology: A Handbook. San Francisco: Jossey-Bass.

Szass, T.S., y Hollender, M.H. (1956). A contribution to the philosophy of medicine: the basic models of the doctor-patient relationship. Arch. Intern. Med., 97, 585-592.

Temkin, O. (1977). The double face of Janus and other essays in the story of medicine. Londres: Baltimore.

Torres, F.I, Carmona, G., López-Briz, E., Abril, V., Ortega, E., y López, A. (1999). Estudio de adhesión al tratamiento antirretroviral en el Hospital General Universitario de Valencia. Publicación Oficial de la Sociedad Española Interdisciplinaria del SIDA, 10, supl.1.

Turk, D., y Meichenbaum, D. (1991). Adherence to self-care regimens: the patient's perspective. En J. Sweet, R. Rozensky y S. Tovian, Handbook of Clinical Psychology in Medical Settings (Cap. 15, pp. 249-266). Nueva York: Plenum Press.

Wagner, G., y Rabkin, J. (2000). Measuring medication adherence: are missed doses reported more accurately than perfect adherence? AIDS Care, 12, 405-408.

Williams, J., y Boykin, F. (1999). The role of social work in HIV/AIDS clinical trials. Social Work in Health Care, 29, 35-56.

Wright, M. (2000). The old problem of adherence: Research on treatment adherence and its relevance for HIV/AIDS. AIDS Care, 12, 703-710. 